\title{
Analisis Kondisi Sosial Dan Pengetahuan Ibu Rumah Tangga Terhadap Pengelolaan Sampah Di Kecamatan Poasia
}

\author{
Wa Ode Uliana ${ }^{1)}$, Ahmad Hidayat ${ }^{2)}$, Anita Indriasary ${ }^{3)}$ \\ 1) Jurusan Geografi FITK Universitas Halu Oleo \\ 2) Jurusan Geografi FITK Universitas Halu Oleo \\ 3) Jurusan Geografi FITK Universitas Halu Oleo
}

Email:waodeuliana@gmail.com

\begin{abstract}
Abstrak: Kondisi fisik lahan perkotaaan semakin sempit dan kurangnya ruang terbuka untuk pengelolaan sampah sehingga perlu ditingkatkan partisipasi masyarkat dalam pengelolaan sampah agar masyarakat mampu secara mandiri peduli terhadap lingkungan. Tujuan penelitian ini,yaitu: (1) untuk mengetahui pengaruh kondisi sosial ibu-ibu rumah tangga di Kecamatan Poasia terhadap pengelolaan sampah; (2) untuk mengetahui pengaruh pengetahun lingkungan ibu-ibu rumah tangga di Kecamatan Poasia terhadap pengelolaan sampah. Metode penelitian ini yaitu metode penelitian kualitatif dengan melakukan analisis regresi linear berganda pada aplikasi SPSS versi 16.0. Hasil penelitian ini antara lain: (1) kondisi sosial ibu-ibu rumah tangga (umur, pendidikan, pekerjaan, dan pendapatan) berpengaruh terhadap pengelolaan sampah. Hal ini dibuktikan dengan uji regresi linear berganda diperoleh nilai signifikan kondisi sosial (X1) adalah sebesar 0,771 dan nilai t hitung sebesar 0,292 ; (2) pengetahuan lingkungan ibu-ibu rumah tangga berpengaruh terhadap pengelolaan sampah. Hal ini dibuktikan dengan hasil uji regresi linear berganda diperoleh nilai signifikan pengetahuan (X2) sebesar 0,000 dan nilai t hitung sebesar 5,565. Oleh karena itu, Kelurahan Anggoeya perlu mendapatkan perhatian khusus oleh pemerintah, karena wilayah tersebut memiliki volume sampah terbesar di Kecamatan Poasia namun kondisi sosial ibu rumah tangga masih lebih rendah jika dibandingkan dengan wilayah lain seperti Kelurahan Anduonohu dan Kelurahan Anggoeya. Selain itu, pengetahuan ibu-ibu rumah tangga di Kelurahan Anggoeya dominan kategori buruk.
\end{abstract}

\section{Kata Kunci: kondisi sosial, pegetahuan, pengelolaan sampah}

\begin{abstract}
The physical condition of urban areas is increasingly narrow and the lack of open space for waste management needs to be increased by community participation in waste management so that the community is able to independently care for the environment. The purpose of this study are: (1) to determining the effect of social conditions of housewives in Poasia District on waste management; (2) to determining the effect of environmental knowledge of housewives in Poasia District on waste management. This research method is a qualitative research method by conducting multiple linear regression analysis on the application of SPSS version 16.0. The results of this study are: (1) the social conditions of housewives (age, education, employment, and income) affect the waste management. This is evidenced by the multiple linear regression test obtained a significant value of social conditions (XI) of 0,771 and $t$ value of 0,292; (2) environmental knowledge of housewives influences waste management. This is evidenced by the results of multiple linear regression tests obtained a significant value of knowledge (X2) of 0,000 and $t$ value of 5,565. Therefore, Anggoeya Village needs to get special attention from the government, because the region has the largest volume of waste in Poasia District, but the social condition of housewives is still lower when compared to other regions such as Anduonohu and Anggoeya. In addition, the knowledge of housewives in Anggoeya Kelurahan is dominant in the bad category.
\end{abstract}

Keywords: social conditions, knowledge, waste management 


\section{PENDAHULUAN}

Kehadiran sampah kota merupakan salah satu persoalan yang dihadapi oleh masyarakat perkotaan, terutama dalam hal penyediaan sarana dan prasarananya. Keberadaan sampah tidak diinginkan bila dihubungkan dengan faktor kebersihan, kesehatan, kenyamanan dan keindahan (estetika). Tumpukan onggokan sampah yang mengganggu kesehatan dan keindahan lingkungan merupakan jenis pencemaran yang dapat digolongkan dalam degradasi lingkungan yang bersifat sosial (Bintarto, 1997).

Dua ratus lima puluh juta jiwa penduduk Indonesia dapat menghasilkan 151.192 ton per hari dengan kebiasaan orang Indonesia membuang sampahnya sembarangan sebanyak 70,31\%. Hal ini menjadikan Indonesia berada pada urutan ketiga tertinggi di dunia sebagai negara terkotor setelah India dan China (Jastam,2015)

Sampah menjadi masalah penting saat ini, terutama untuk kota-kota besar yang padat penduduknya. Bahkan sampah bisa menjadi persoalan krusial, jika tidak ditangani serius. Sebab dampaknya bisa mengganggu infrastruktur kota, termasuk kerawanan kesehatan masyarakat dan lingkungan hidup. Volume rata-rata sampah di Indonesia mencapai 200 ribu ton per hari. Daerah perkotaan yang menyumbang sampah paling banyak. Berbagai kendala masih dihadapi dalam melaksanakan pengelolaan sampah tersebut baik kendala ekonomi, sosial budaya maupun penerapan teknologi (Saputra, 2017).

Meningkatnya volume sampah dari kegiatan penduduk berimbas terhadap lahan tempat pembuangan akhir (TPA) sampah juga makin terbatas. Kondisi ini akan semakin buruk apabila dalam pengelolaan sampah di masing-masing daerah masih kurang efektif, efisien dan berwawasan lingkungan serta tidak terkoordinasi dengan baik (Rudianto, 2005).
Pengelolaan sampah sebenarnya telah diatur pemerintah melalui UndangUndang Republik Indonesia Nomor 18 Tahun 2008 bahwa pengelolaan sampah tidak hanya menjadi kewajiban pemerintah saja tetapi, masyarakat dan pelaku usaha sebagai penghasil sampah juga bertanggung jawab menciptakan lingkungan yang bersih dan sehat. Pemerintah melalui UU tersebut memberi ruang yang cukup banyak bagi pemerintah provinsi, kotamadya/ kabupaten untuk merencanakan dan mengelola sampah dalam kawasanya.

Kepedulian masyarakat dalam pengelolaan sampah sangat diperlukan untuk membantu pemerintah dalam menangani permasalahan sampah. Kurangnya partisipasi masyarakat dalam pengelolaan sampah merupakan kendala terpenting dalam menangani permasalahan sampah. Mengingat kondisi fisik perkotaan yang lahannya semakin sempit dan kurangnya ruang terbuka untuk pengelolaan sampah sehingga perlu ditingkatkan partisipasi masyarkat dalam pengelolaan sampah agar masyarakat mampu secara mandiri peduli terhadap lingkungan.Untuk mewujudkan kondisi lingkungan yang bersih dan sehat maka perlu adanya partisipasi dari berbagai pihak baik dari pemerintah maupun masyarakat khususnya dalam pengelolaan sampah perkotaan. Permasalahan dalam pengelolaan sampah perkotaan tidak hanya terjadi di kota-kota besar, namun juga terjadi di kota-kota kecil dan daerah yang mempunyai kepadatan penduduk cukup tinggi dan adanya aktifitas perekonomian yang tinggi pula. Seperti halnya yang terjadi di Kecamatan Poasia Kota Kendari terdapat permasalahan pembuangan dan pengolahan sampah. Meningkatnya jumlah penduduk menjadi faktor meningkatnya jumlah sampah yang ada.

Timbulnya masalah sampah di Kecamatan Poasia, diduga tidak lepas dari berbagai faktor antara lain kurangnya pengetahuan tentang lingkungan dan faktor sosial masyarakat. Menurut Suparmoko 
(2000) bahwa faktor lain dari permasalahan pengelolaan sampah,adalah masyarakat masih cenderung menganggap bahwa pengelolaan sampah semata-mata merupakan tanggung jawab Pemerintah Kota.

Pertumbuhan jumlah penduduk yang tinggi dinegara berkembang turut meningkatkan jumlah sampah yang dihasilkan. Pertumbuhan rata-rata penduduk Kecamatan Poasia dalam kurun waktu 2017 sampai 2018 adalah sebesar $1,48 \%$. Peningkatan populasi penduduk ini berimplikasi terhadap peningkatan jumlah produksi sampah Kecamatan Poasia yaitu sebesar 2,835\% selama tahun $2016\left(4.274 \mathrm{~m}^{3} /\right.$ hari) $\quad$ sampai 2017 $\left(4.520 \mathrm{~m}^{3} /\right.$ hari) atau $1000-1500$ ton perhari. Sementara laju peningkatan sampah 8\%-12 $\%$ per tahun (Badan Pusat Statistik Kota Kendari, 2017)

Berdasarkan latar belakang di atas, bahwa sumber terbesar dari permasalahan sampah adalah sampah rumah tangga dan berbagai upaya yang telah dilakukan oleh pemerintah untuk meningkatkan cara pengelolaannya, tetapi belum memperoleh hasil yang maksimal. Ibu rumah tangga dianggap memiliki hubungan langsung dan tanggungjawab yang tinggi melebihi anggota keluarga yang lain dalam proses penimbunan dan pengelolaannya. Melihat kondisi tersebut maka perlu di lakukan penelitian tentang "Analisis Kondisi Sosial dan Pengetahuan Lingkungan Ibu-ibu Rumah Tangga Terhadap Pengelolaan Sampah di Kecamatan Poasia". Tujuan dari penelitian ini yaitu untuk mengetahui pengaruh kondisi sosial ibu-ibu rumah tangga di Kecamatan Poasia terhadap pengelolaan sampah serta untuk mengetahui pengaruh pengetahun lingkungan ibu-ibu rumah tangga di Kecamatan Poasia terhadap pengelolaan sampah.

\section{METODE PENELITIAN}

Penelitian ini dilakukan di Kecamatan Poasia Kota Kendari Provinsi Sulawesi Tenggara pada bulan September-
Desember Tahun 2019. Kecamatan Poasia terdiri atas Kelurahan Annggoeya, Kelurahan Matabubu Keluraan Adonuohu dan Eeluraan Rahandouna (Gambar 1).

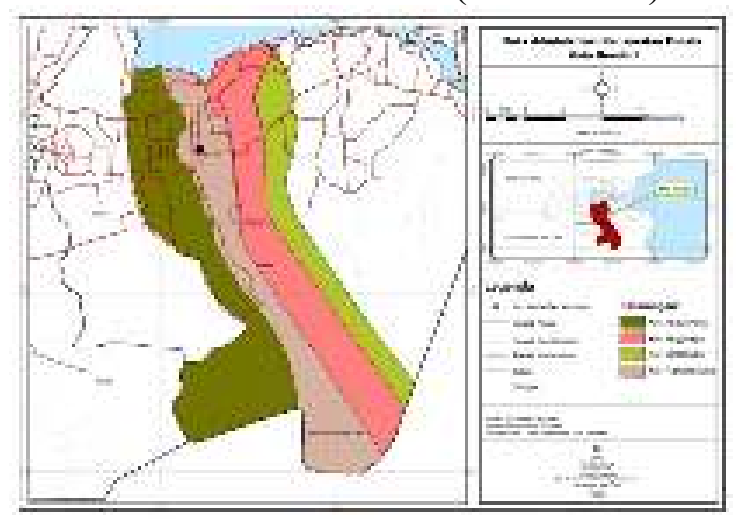

Gambar 1.Peta Lokasi Penelitian

\subsection{Data Penelitian}

Data yang digunakan dalam penelitian ini menggunakan data primer dan data sekunder.

\section{Data Primer}

Data primer merupakan data yang diperoleh langsung dilapangan. Data primer yang digunakan dalam penelitian ini adalah pernyataan responden terhadap kondisi sosial dan pengtahuan tentang sampah terhadap pengelolaan sampah. Data tersebut diperoleh dengan cara kuesioner.

\section{Data Sekunder}

Data sekunder yaitu data yang sudah tersedia. Data sekunder merupakan data pendukung bagi data primer yang diperoleh dari literatur-literatur dan dokumen-dokumen yang berhubungan dengan permasalahan yang diteliti. Data sekunder yaitu data yang diperoleh dari instasi-instansi terkait. Adapun data sekunder yang digunakan dalam penelitian ini adalah data jumlah rumah tangga, serta peta administrasi Kecamatan

\subsection{Tahapan Pengolahan Data}

Pengelohan data dalam penelitian dilakukan dengan menggunakan aplikasi SPSS versi 16.0. Data responden yang telah terkumpul kemudian ditabulasi berdasarkan masing-masing kategori. Setelah semua data kuesioner telah 
terkumpul, maka langkah selanjutnya yaitu melakukan analisis berdasarkan ketentuan yang berlaku.

\subsection{Metode Analisis Data}

Analisis data yang digunakan dalam penelitian ini dilakukan dengan dua tahapan yaitu :

\section{Jumlah Sampah}

Berdasarkan SNI 19-3983-1995, bila pengamatan lapangan belum tersedia, maka untuk menghitung besaran timbulan sampah, dapat digunakan angka timbulan sampah sebagai berikut :

- Satuan timbulan sampah kota sedang = $2,75-3,25$ liter/orang/hari $=0,7-0,8$ $\mathrm{kg} /$ orang/hari

- Satuan timbulan sampah kota kecil $=2,5$ $-2,75$ liter/orang/hari $=0,625-0,7$ $\mathrm{kg} /$ orang/hari.

Untuk menghitung timbunan sampah di Kecamatan Poasia maka digunakan persamaan sebagai berikut:

$$
\mathrm{Vs}=P_{0} \times V(2)
$$

Keterangan :

$\mathrm{Vs}=$ Volume Timbulan sampah

$P_{0}=$ Jumlah penduduk

$V=$ rata-rata volume sampah $(2,97$

liter/orang/hari)

\section{Kondisi Sosial dan Pengetahuan Ibu-ibu Rumah Tangga}

Pengaruh kondisi sosial dan pengetahuan ibu-ibu rumah tangga terhadap pengelolaan sampah diiktahui dengan cara mendeskripsikan tentang kondisi sosial, tingkat pengetahuan lingkungan dan cara pengelolaan sampah ibu rumah tangga serta mendeskripsikan hubungan antara variabel bebas berupa kondisi sosial (X1), pengetahuan (X2), dengan variabel terikat berupa pengelolaan sampah rumah tangga $(\mathrm{Y})$.

Penelitian ini mengambil wilayah penelitian Kecamatan Poasia dengan populasi seluruh ibu-ibu rumah tangga. Pengambilan sampel area menggunakan Purposive Random Sampling. Data diambil dengan menggunakan instrument berupa kuesioner. Kemudian data mentah yang terkumpul dimasukkan dalam tabulasi tunggal kemudian dianalisis menggunakan teknik analisis regresi linier berganda. Data yang terkumpul dilakukan kategorisasi berdasarkan jawaban responden. Jawaban yang baik atau benar akan diberi skor 1 sedangkan jawaban yang buruk atau salah akan diberi skor 0. Setelah seluruh pernyataan responden telah diberi skor berdasarkan jawaban masing-masing responden, maka seluruh jawaban responden akan ditabulasi dan akan dihitung interval kelas pengaruh masingmasing variabel $\mathrm{X}$ terhadap variabel $\mathrm{Y}$. Interval kelas dapat diketahui dengan menggunakan persamaan sebagai berikut.

$$
\mathrm{I}=\frac{\text { Skor tertinggi }- \text { skor terendah }}{\text { Jumlah Kelas }}
$$

Sebagaimana analisis data kuantitatif akan pengujian hipotesis, maka terlebih dahulu akan dilakukan pengujian instrumen data melalui uji validitas dan uji reliabilitas. Uji validitas bertujuan untuk mengetahui apakah alat ukur yang digunakan tepat untuk mengukur apa yang akan diukur. Dasar pengambilan keputusan :

- Jika rhitung> rtabel, maka variabel tersebut dinyatakan valid

- Jika rhitung <rtabel, maka variabel tersebut dinyatakan tidak valid

Reliabilitas

mengandung pengertian bahwa suatu penelitian dapat dipercaya atau dapat digunakan sebagai alat pengumpul data karena instrument tersebut sudah baik. Reliabilitas menunjuk pada tingkat keterandalan sesuatu. Reliabel artinya dapat dipercaya jadi dapat diandalkan (Arikunto, 2006). Uji reliabilitas dilakukan dengan menggunakan rumus alpha. Instrumen dapat dikatakan reliable jika nilai $r$ alpha $>$ rtabel.

Setelah uji validitas dan reliabel telah dilakukan, maka uji hipotesis dapat dilakukan. Uji hipotesisi dapat dibagi menjadi uji parsial (Uji T) dan uji simultan (Uji F).Uji $\mathrm{T}$ variabelpada dasarnya menunjukkan seberapa jauh pengaruh satuvariabel bebas secara individual dalam menerangkan variasi variabel independen. 
| Vol.5 | No.2| 2021

Asumsi dalam menilai pengaruh satu variabel bebas terhadap variabel terikat adalah sebagai berikut.

- Jika nilai sig<0,05 atau $\mathrm{t}$ hitung $>\mathrm{t}$ tabel, maka terdapat pengaruh variabel $\mathrm{X}$ terhadap variabel $\mathrm{Y}$.

- Jika nilai sig $>0,05$ atau $\mathrm{t}$ hitung $<\mathrm{t}$ table, maka tidak terdapat pengaruh variabel $\mathrm{X}$ terhadap variabel $\mathrm{Y}$.

Sedangkan Uji F digunakan untuk mengetahui kondisi sosial (X1) dan Pengetahun (X2) berpengaruh secara simultan terhadap pengelolaan sampah (Y) di Kecamatan Poasia. Asumsi dalammenilai pengaruh simultan variabel $\mathrm{X} 1$ dan $\mathrm{X} 2$ terhadap variabel Yyaitu sebagai berikut:

- Jika nilai sig<0,05 atau $F$ hitung $>$ Ftabel, maka terdapat pengaruh variabel $\mathrm{X}$ secara simultan terhadap variabel $\mathrm{Y}$.

- Jika nilai sig $>0,05$ atau $F$ hitung $<$ Ftabel, maka tidak terdapat pengaruh variabel $\mathrm{X}$ secara simultan terhadap variabel Y.

\section{HASIL DAN PEMBAHASAN}

\subsection{Jumlah Sampah Menurut Kelurahan di Kecamatan Poasia}

Berikut ini hasil perhitungan volume timbunan sampah di Kecamatan Andonuohu Kecamatan Poasia berdasarkan jumlah penduduk pada tahun 2018.

$$
\begin{aligned}
& \mathrm{Vs}=P_{0} \times V \ldots \ldots \ldots .(2) \\
& =11.802 \times 2,97 \\
& =35.052 \text { liter/hari. }
\end{aligned}
$$

Maka, jumlah volume sampah di Keluarahan Anduonohu Kecamatan Poasia adalah 35.052 liter/hari. Dengan menggunakan cara yang sama, maka diperoleh hasil perhitungan volume sampah menurut keluarahan di Kecamatan Poasia seperti yang telah disajikan pada Tabel 1 berikut ini.

Tabel 1. Rata-rata Volume Sampah Menurut Keluarahan

\begin{tabular}{llrl}
\hline Kelurahan & (P) & (V) & (Vs) \\
\hline Anduonohu & 11802 & 2,97 & $35.051,94$ \\
\hline Rahandouna & 12807 & 2,97 & $38.036,79$ \\
\hline
\end{tabular}

\begin{tabular}{lrrr}
\hline Anggoeya & 5835 & 2,97 & $17.329,95$ \\
\hline Matabubu & 1489 & 2,97 & $4.422,33$ \\
\hline Total & $\mathbf{3 1 9 3 3}$ & $\mathbf{2 , 9 7}$ & $\mathbf{9 4 . 8 4 1 , 0 1}$
\end{tabular}

Sumber: Hasil Analisis Data Sekunder, 2019

Berdasarkan hasil perhitungan diatas, volume sampah terbanyak hingga yang terkecil berturut-turut yaitu Kelurahan Rahandouna sebanyak 38.036,79 liter/hari, keluarahan Anduonohu sebanyak 35.051,94 liter/hari, Keluarahan Anggoeya sebanyak 17,329,95 liter/hari, dan Keluarahan Matabubu sebanyak 4.422,33 liter/hari. Jumlah volume sampah di Kecamatan Poasia yaitu 94.841,01 liter/hari. Gambarana volume sampah di Kecamatan Poasia telah disajikan pada Gambar 2 berikut.

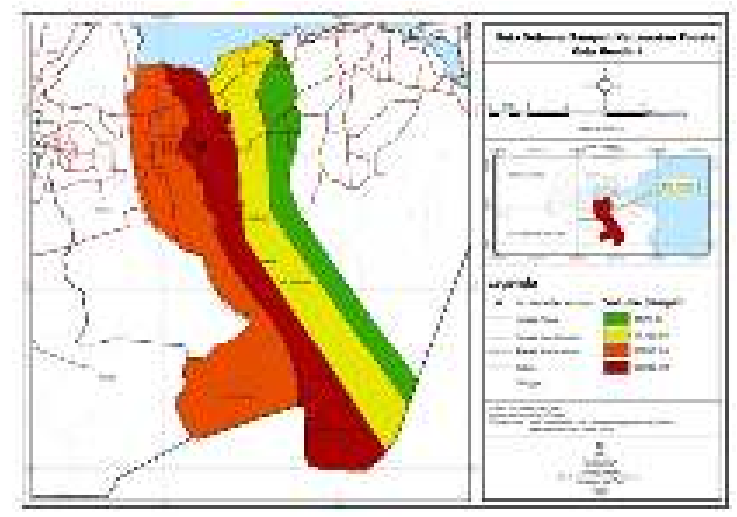

Gambar 2. Peta Volume Sampah di Kecamatan Poasia

Pada gambar di atas wilayah dengan polygon berwarna merah menunjukan volume sampah paling banyak yaitu $38.036,79$ liter/hari, polygon berwarna kuning sebanyak 35.051,94 liter/hari, polygon berwarna orange sebanyak 17,329,95 liter/hari, dan polygon berwarna hijau memiliki volume sampah terendah yaitu sebanyak 4.422,33 liter/hari.

\subsection{Kondisi Sosial dan Pengetahuan Ibu Rumah Tangga di Kecamatan Poasia \\ Deskripsi Variabel Kondisi Sosial (X1)}

Gambaran tentang kondisi sosial ibu-ibu rumah tangga di Kecamatan Poasia telah disajikan pada Tabel 2 berikut ini.

Tabel 2. Kondisi Sosial (X1)

\begin{tabular}{lcc}
\hline Variabel X & N & \% \\
& & Oktober--- 145
\end{tabular}




\begin{tabular}{lll}
\hline Umur & & \\
\hline Baik ( $>50$ tahun) & 217 & 56,66 \\
\hline Buruk (<50 tahun) & 166 & 43,34 \\
\hline Pendidikan & & \\
\hline $\begin{array}{l}\text { Akademi/Perguruan } \\
\text { Tinggi (Baik) }\end{array}$ & 267 & 69,71 \\
\hline Sedang (SLTP/SMA) & 43 & 11,22 \\
\hline $\begin{array}{l}\text { Buruk (Tidak } \\
\text { Tamat/Tamat SD) }\end{array}$ & 73 & 19,06 \\
\hline Pekerjaan & & \\
\hline Bekerja (Baik) & 339 & 88,51 \\
\hline $\begin{array}{l}\text { Tidak bekerja } \\
\text { (Buruk) }\end{array}$ & 44 & 11,49 \\
\hline $\begin{array}{ll}\text { Pendapatan } \\
\text { >Rp. 2.000.000 }\end{array}$ & 283 & 73,89 \\
(Baik) & & \\
\hline $\begin{array}{l}<\text { Rp. 2.000.000 } \\
\text { (Buruk) }\end{array}$ & 100 & 26,11 \\
\hline
\end{tabular}

Sumber: Hasil Analisis Data Primer, 2019.

Pada variabel X1 di atas, masingmasing jawaban responden akan diberi skor. Jika jawaban responden baik maka akan diberi skor 1 , jika jawaban responden sedang maka akan diberi skor 0,5 dan jika jawaban responden buruk maka akan diberi skor 0. Hasil dari nilai bobot responden tentang variabel penelitian di kategorikan kedalam 2 kelas yaitu baik dan buruk. Persamaan yang digunakan untuk menghitung interval kelas yaitu:

\section{$\mathrm{I}=\underline{\text { Skor tertinggi }- \text { skor terendah }}$} Jumlah Kelas

Gambaran kondisi sosial menurut keluarahan ibu-ibu rumah tangga di Kecamatan Poasia telah disajikan pada tabel berikut ini.

Tabel 3. Kriteria Kondisi Sosial Menurut

\begin{tabular}{|c|c|c|c|c|}
\hline \multicolumn{5}{|c|}{ Keluarahan } \\
\hline Keluarahan & I & Kriteria & $\mathbf{F}$ & $(\%)$ \\
\hline \multirow[b]{2}{*}{ Anduonohu } & $2,26-4$ & Baik & 151 & 92,64 \\
\hline & $0,5-2,25$ & Buruk & 12 & 7,36 \\
\hline \multirow[t]{2}{*}{ Jumlah } & & & 163 & 100 \\
\hline & $2,1-4$ & Baik & 73 & 55,20 \\
\hline Rahandouna & $0-2$ & Buruk & 59 & 44,70 \\
\hline \multirow[t]{2}{*}{ Jumlah } & & & 132 & 100 \\
\hline & $2,26-4$ & Baik & 43 & 59,72 \\
\hline \multirow{2}{*}{$\begin{array}{l}\text { Anggoeya } \\
\text { Jumlah } \\
\end{array}$} & $0,5-2,25$ & Buruk & 29 & 40,28 \\
\hline & & & 72 & 100 \\
\hline \multirow{3}{*}{$\begin{array}{l}\text { Matabubu } \\
\text { Jumlah }\end{array}$} & $2,1-4$ & Baik & 8 & 50 \\
\hline & $0-2$ & Buruk & 8 & 50 \\
\hline & & & 16 & 100 \\
\hline
\end{tabular}

Sumber: Hasil Analisis Data Primer, 2019.

Deskripsi Variabel Pengetahuan (X2)

Gambaran tentang pengetahuan ibu-ibu rumah tangga di Kecamatan Poasia telah disajikan pada Tabel 4 berikut ini.

Tabel 4. Variabel Pengetahuan (X2)

\begin{tabular}{llll}
\hline Pertanyaan & Jawaban & $\mathbf{N}$ & $\mathbf{\%}$ \\
\hline \multirow{2}{*}{2} & Baik & 329 & 85,90 \\
\cline { 2 - 4 } & Buruk & 54 & 14,10 \\
\hline \multirow{2}{*}{3} & Baik & 110 & 47,00 \\
\cline { 2 - 4 } & Buruk & 203 & 53,00 \\
\hline 4 & Baik & 189 & 49,35 \\
\cline { 2 - 4 } & Buruk & 194 & 50,65 \\
\hline 5 & Baik & 219 & 57,18 \\
\cline { 2 - 4 } & Buruk & 164 & 42,82 \\
\hline 6 & Baik & 196 & 51,17 \\
\cline { 2 - 4 } & Buruk & 187 & 48,83 \\
\hline 7 & Baik & 167 & 43,60 \\
\cline { 2 - 4 } & Buruk & 216 & 56,40 \\
\hline 8 & Baik & 182 & 47,52 \\
\cline { 2 - 4 } & Buruk & 201 & 52,48 \\
\hline 9 & Baik & 200 & 52,22 \\
\cline { 2 - 4 } & Buruk & 183 & 47,78 \\
\hline \multirow{2}{*}{5} & Baik & 187 & 48,83 \\
\cline { 2 - 4 } & Buruk & 196 & 51,17 \\
\hline
\end{tabular}

Sumber: Hasil Analisis Data Primer, 2019.

Gambaran pengetahuan menurut keluarahan ibu-ibu rumah tangga di Kecamatan Poasia telah disajikan pada tabel berikut ini.

Tabel 5. Kriteria Pengetahun Menurut Keluarahan

\begin{tabular}{|c|c|c|c|c|}
\hline Keluarahan & $\mathbf{i}$ & Kriteria & $\mathbf{F}$ & $(\%)$ \\
\hline & $5,1-8$ & Baik & 63 & 38,65 \\
\hline Anduonohu & $2-5$ & Buruk & 100 & 61,35 \\
\hline \multirow[t]{2}{*}{ Jumlah } & & & 163 & 100 \\
\hline & $5,6-9$ & Baik & 56 & 42,4 \\
\hline Rahandouna & $2-5,5$ & Buruk & 76 & 57,56 \\
\hline \multirow[t]{2}{*}{ Jumlah } & & & 132 & 100 \\
\hline & $5,1-8$ & Baik & 30 & 41,67 \\
\hline Anggoeya & $2-5$ & Buruk & 42 & 58,33 \\
\hline \multirow[t]{2}{*}{ Jumlah } & & & 72 & 100 \\
\hline & $5,1-8$ & Baik & 5 & 31,25 \\
\hline Matabubu & $2-5$ & Buruk & 11 & 68,17 \\
\hline Jumlah & & & 16 & 100 \\
\hline
\end{tabular}

Sumber: Hasil Analisis Data Primer, 2019.

Variabel Pengelolahan Sampah (Y)

Gambaran tentang variabel

pengelolaan sampah di Kecamatan Poasia telah disajikan pada Tabel 6 berikut ini.

Tabel 6. VariabelPengelolaan Sampah (Y) 


\begin{tabular}{llll}
\hline Pertanyaan & Jawaban & \multicolumn{1}{c}{$\mathbf{N}$} & $\mathbf{\%}$ \\
\hline \multirow{2}{*}{1} & Ya & 328 & 85,64 \\
\cline { 2 - 4 } & Tidak & 55 & 14,36 \\
\hline 2 & Ya & 316 & 82,51 \\
\cline { 2 - 4 } & Tidak & 67 & 17,49 \\
\hline 3 & Ya & 208 & 54,31 \\
\cline { 2 - 4 } & Tidak & 175 & 45,69 \\
\hline 4 & Ya & 219 & 57,18 \\
\cline { 2 - 4 } & Tidak & 164 & 42,82 \\
\hline 5 & Ya & 225 & 58,75 \\
\hline 6 & Tidak & 158 & 41,25 \\
\hline \multirow{2}{*}{6} & Ya & 152 & 39,69 \\
\cline { 2 - 4 } & Tidak & 231 & 60,31 \\
\hline \multirow{2}{*}{ Sul }
\end{tabular}

Sumber: Hasil Analisis Data Primer, 2019. Gambaran pengetahuan menurut keluarahan ibu-ibu rumah tangga di Kecamatan Poasia telah disajikan pada tabel berikut ini.

Tabel 7 Kriteria Pengelolaan Sampah Menurut Keluarahan

\begin{tabular}{|c|c|c|c|c|}
\hline Keluarahan & I & Kriteria & $\mathbf{F}$ & $(\%)$ \\
\hline \multirow{3}{*}{$\begin{array}{l}\text { Anduonohu } \\
\text { Jumlah }\end{array}$} & $0-3$ & Baik & 92 & 56,44 \\
\hline & $3,1-6$ & Buruk & 71 & 43,56 \\
\hline & & & 163 & 100 \\
\hline \multirow[b]{2}{*}{ Rahandouna } & $0-3$ & Baik & 73 & 55,30 \\
\hline & $3,1-6$ & Buruk & 59 & 44,70 \\
\hline Jumlah & & & 132 & 100 \\
\hline \multirow[b]{2}{*}{ Anggoeya } & $0-3$ & Baik & 41 & 56,94 \\
\hline & $3,1-6$ & Buruk & 31 & 43,06 \\
\hline \multirow[t]{2}{*}{$\begin{array}{l}\text { Jumlah } \\
\end{array}$} & & & 72 & 100 \\
\hline & $1-3,5$ & Baik & 10 & 62,50 \\
\hline Matabubu & $\begin{array}{ll}3,51 & - \\
6 & \end{array}$ & Buruk & 6 & 37,50 \\
\hline Jumlah & & & 16 & 100 \\
\hline
\end{tabular}

Sumber: Hasil Analisis Data Primer, 2019.

\section{Uji Parsial (Uji T)}

Uji parsial (Uji T) menunjuan hasil sebagai berikut.

Tabel 8. Hasil Uji Hipotesis X1 dan X2

\begin{tabular}{|c|c|c|c|c|c|}
\hline \multicolumn{6}{|c|}{ Coefficients $^{a}$} \\
\hline \multirow[b]{2}{*}{ Model } & $\begin{array}{r}\text { Unsta } \\
\mathrm{Coc}\end{array}$ & $\begin{array}{l}\text { ndardized } \\
\text { fficients }\end{array}$ & $\begin{array}{l}\text { Standar } \\
\text { dized } \\
\text { Coeffici } \\
\text { ents }\end{array}$ & & \\
\hline & B & Std. Error & Beta & $\mathrm{t}$ & Sig. \\
\hline $\begin{array}{l}1 \text { (Const } \\
\text { ant) }\end{array}$ & 2.550 & .370 & & 6.894 & .000 \\
\hline $\mathrm{X} 1$ & .031 & .108 & .014 & .292 & .771 \\
\hline $\mathrm{X} 2$ & .237 & .043 & .275 & 5.566 & .000 \\
\hline
\end{tabular}

Sumber: Hasil Analisis Data Primer, 2019.

Berdasarkan tabel 8 di atas diperoleh persamaan regresi $\mathrm{Y}=2,550+$ $0,031 \mathrm{X} 1+0,237 \mathrm{X} 2+$ e. Pada persamaan regresi dihasilkan koefisien regresi adalah 2,550. Variabel bebas kondisi sosial (X1) memiliki pengaruh yang positif terhadap variabel terikatnya, begitupun variabel pengetahuan (X2) memiliki pengaruh yang positif terhadap variabel terikat (Y).Variabel bebas kondisi sosial (X1) memiliki pengaruh yang positif terhadap variabel terikatnya artinya jika setiap satu poin kondisi sosial (X1) maka nilai pengelolaan sampah bertambah sebesar 0,031 dengan ketentuan nilai-nilai variabel lain tetap. Begitupun variabel pengetahuan (X2) memiliki pengaruh yang positif terhadap variabel terikat (Y), artinya bahwa jika setiap satu poin pengetahuan (X2) maka nilai pengelolaan sampah (Y) bertambah sebesar 0,237 dengan ketentuan nilai-nilai variabel lain tetap.

Diketahui nilai sig. untuk pengaruh kondisi sosial (X1) terhadap pengelolaan sampah (Y) adalah sebesar 0,771 dan nilai $t$ hitung sebesar 0,292. Berdasarkan hasil diatas, sig $>0,05$ dan $\mathrm{t}$ hitung $>\mathrm{t}$ table $(\mathrm{t}$ tabel $=1,697903)$. Nilai $\mathrm{t}$ hitung $>\mathrm{t}$ tabel, maka terdapat pengaruh variabel kondisi sosial (X1) terhadap variabel pengelolaan sampah ( Y).

Diketahui nilai sig. untuk pengaruh pengetahuan (X2) terhadap pengelolaan sampah ( $\mathrm{Y}$ ) adalah sebesar 0,000 dan nilai $t$ hitung sebesar 5,565. Berdasarkan hasil diatas, sig $<0,05$ dan $\mathrm{t}$ hitung $>\mathrm{t}$ table $(\mathrm{t}$ tabel $=1,697903)$. Sehingga,terdapat pengaruh variabel pengetahuan (X2) terhadap variabel pengelolaan sampah ( $\mathrm{Y}$ ).

\section{Uji Simultan (Uji F)}

Adapun hasil hipotesis secara simultan dapat dilihat pada tabel sebagai berikut.

Tabel 9. Hasil Uji Hipotesis ketiga (H3)

\begin{tabular}{llllll}
\hline \multicolumn{5}{c}{ ANOVA $^{\mathbf{b}}$} \\
\hline Model & Sum of & & Mean & & \\
Squares & df & Square & F & Sig. \\
\hline
\end{tabular}




\begin{tabular}{lrrrr}
\hline Regression & 111.971 & 2 & 55.985 & 15.6 \\
& & & & \\
& & $000^{\mathrm{a}}$ \\
\hline Residual & 1357.606 & 380 & 3.573 & \\
\hline Total & 1469.577 & 382 & & \\
\hline
\end{tabular}

a. Predictors:

(Constant), X2, X1

b. Dependent Variable: $\mathrm{Y}$

Sumber: Hasil Analisis Data Primer, 2019.

Berdasarkan tabel di atas, diperoleh nilai sig. yaitu 0,000 dan nilai f hitung sebesar $15,671 \quad(\mathrm{t}$ tabel $=1,697903)$. Nilai sig $<0,005$ dan nilai $\mathrm{f}$ hitung $>\mathrm{f}$ tabel, maka terdapat pengaruh signifikan secara simultan variabel kondisi sosial (X1) dan variabel pengetahuan (X2) terhadap variabel pengelolaan sampah (Y).

\section{KESIMPULAN}

Berdasarkan hasil penelitian yang telah dilakukan, maka kesimpulan dari penelitian ini yaitu: (1) kondisi sosial ibuibu rumah tangga (umur, pendidikan, pekerjaan, dan pendapatan) berpengaruh terhadap pengelolaan sampah. Hal ini dibuktikan dengan uji regresi linear berganda diperoleh nilai signifikan kondisi sosial (X1) adalah sebesar 0,771 dan nilai t hitung sebesar 0,292; (2) pengetahuan lingkungan ibu-ibu rumah tangga berpengaruh terhadap pengelolaan sampah. Hal ini dibuktikan dengan hasil uji regresi linear berganda diperoleh nilai signifikan pengetahuan (X2) sebesar 0,000 dan nilai $t$ hitung sebesar 5,565.

\section{DAFTAR PUSTAKA}

Arikunto,2006. Prosedur Penelitian Suatu Pendekatan Praktik ( Edisi Revisi VI). PT Rineka Cipta Jakarta.

Badan Pusat Statistik Kota Kendari. 2019. Kecamatan Poasia Dalam Angka Tahun 2018. Kendari. BPS Kota Kendari.

Bintarto, 1997. Geografi Kota, Pengantar Cetakan Pertama. Yogyakarta. Spring.

Jastam, Muh. Saleh. 2015.Pemberdayaan Masyarakat Melalui Pengelolaan Sampah Studi Kasus Di Bank Sampah
Pelita Harapan, Kelurahan Ballaparang, Kecamatan Rappocini, Makassar.Vol 1, No. 1.

Rudianto Dan Azizah. 2005. Perbedaan Jarak Perumahan Ke TPA Sampah Open Jumping Dengan Indikator Tingkat Kepadatan Lalat Dan Kejadian Diare ( Studi: Desa Kenet Kecamatan Beji Kabupaten Pasuruan). Jurnal Kesehatan Lingkungan:152-155.

Saputra, Surahman. 2017. Pengetahuan Sikap Dan Perilaku Pengelolaan Sampah Pada Karyawan Di Kampus. Fakultas Kesehatan Masyarakat . Universitas Ahmad Dahlan.

Suparmoko. 2000. Ekonomika Lingkungan. Edisi 1. Yogyakarta: BPTE.

Undang-Undang Republik Indonesia Nomor 18 Tahun 2008.Tentang Pengelolaan Sampah.7 Mei 2008.Dewan Perwakilan Rakyat Republik Indonesia dan Presiden Republik Indonesia. Jakarta. 